\title{
Improving rural broadband deployment with synergistic effects between multiple fixed infra-structures
}

\author{
Felix Limbach
}

Technical University Berlin

felix.limbach@tu-berlin.de

\author{
Hannes Kuebel \\ Technical University Berlin
}

\section{Rüdiger Zarnekow}

Technical University Berlin

\section{Abstract}

The utilization of deployment synergies across infrastructure networks of different industries has been identified as a key to improve the broadband business case. Thus, an increasing number of broadband plans require owners of physical infrastructures such as the electricity, pipeline, highway and railroad networks to host broadband infrastructure. However, crossindustry cooperation brings about new complexity to optimal utilization of deployment synergies.

This paper explores cost savings that can be achieved if national non-telecommunication infrastructures are considered as source for broadband networks in rural areas. Moreover, it assesses economic, political and regulatory measures required for improving synergy utilization. The presented approach is based on a techno-economic broadband deployment model, which is applied to all rural communities in Germany. Results indicate that synergy optimized network topologies can generally decrease rural broadband deployment cost. However, it is required that local authorities recognize the definition of broadband tender areas as a chance for the aggregation of demand. Moreover, national regulators need to ensure that metro-aggregation, backbone and co-location costs, which are associated with nontelecommunication infrastructures, do not exceed the costs of the incumbent by more than $50 \%$.

Keywords: broadband; rural; synergy evaluation; regulation; policy

\section{Introduction}

Telecommunication networks are widely considered as a basis for economic grouth and associated with high general economic benefits (EC, 2012b; Ruhle, Brusic, Kittl, \& Ehrler, 2011). Consequently, governments around the world define broadband plans to improve the availability of those infrastructures (Falch \& Henten, 2010). The European Commission has initiated the Digital Agenda to foster the provisioning of download rates of up to $100 \mathrm{Mbps}$ for European citizens (EC, 2010a). Similarly, the Australian government has proposed the 2016 Corporate Plan for Australia's broadband network (NBNCO, 2015).

Irrespective of the employed fibre deployment variant and technology cost modelling, studies have repeatedly highlighted the economic challenges associated with rural broadband deployment (Analysys Mason, 2008, Chatzi, Lazaro, Prat, \& Tomkos, 2013; Hoernig et al., 2012; Rokkas, Katsianis, \&Varoutas, 2010). In themost sparsely populated areas, even a single infrastructure operator with a high market share may require public funding to become economically viable.

However, to limit negative market effects and reduce aid to the necessary minimum all cost reduction measures should be exhausted before public funding is granted for a project (EC, 2013b). Accordingly, recent proposals of the European Commission suggest a variety of measures to maximize synergy utilization across physical networks (EC, 2013c). In this case regulation goes beyond the telecommunication sector and requires owners of physical 
infrastructures such as the electricity, pipeline, highway or railway network to host broadband infrastructures. Similarly, the Australian broadband plan denotes access to existing areal infrastructures of utilities as a key enabler for the national broad strategy (NBNCO, 2015).

The majority of broadband models consider mark-downs on calculations of a given greenfield network topology to account for synergy utilization in certain segments of the telecommunication access network (Analysys Mason, 2008; Chatzi et al., 2013; J ay, Neumann, \&Plückebaum, 2014). Moreover, cross-network synergy utilization in broadband deployment has been addressed for a combined network roll out scenario of utility and telecommunication companies (Tahon et al., 2014).

However, literature that assesses economic, political and regulatory implications associated with using national physical infrastructures such as railroads, highways, pipelines, power lines or railways as a fibre backbone in rural areas is hardly available. This contribution aims to fill this gap and will subsequently denote those infrastructures as alternative infrastructures. In the course of this paper, the following questions are explored:

What is the financial magnitude of cost savings if alternative national infrastructures are considered as source for broadband networks in rural areas? What political and regulatory actions are required to fully leverage the cost reduction measures?

The presented questions are addressed with a street-length aware synergy evaluation model based on OpenStreetMap (OSM), i.e., an open-source geographical information system (GIS).

This article is structured into the following sections. The next section provides details on theoretical foundations and related work, and Section 3 explains the considered deployment scenarios. Section 4 presents the synergy evaluation model. In its subsections, first, a detailed overview of the model input is provided, and second, an internet access model is presented. Subsequently, the model results are presented and discussed with respect to geographical preconditions for synergy utilization, topology characteristics and achievable cost advantages. Thereafter, political and regulatory implications are discussed in Section 6. Finally, Section 7 provides conclusions regarding the research objectives.

\section{Theoretical foundations and related work}

\subsection{Characteristics of rural network topologies}

Generally, telecommunication access networks can make use of coaxial cables, power line communications, wireless solutions and copper or fibre cables. Of all available options, Fibreto-the-Home (FTTH) is recognized as the most future-proof and reliable solution for broadband access. However, due to the high deployment costs, national broadband markets currently reach FTTH saturation at a share of $20 \%$ (FTTH Council Europe, 2013). Especially for rural areas, Fibre-to-the-Cabinet (FTTC) and Fibre-to-the-Building (FTTB) have been proposed as intermediate steps in a gradual FTTH deployment process (Analysys Mason, 2008). On average, they are up to 75\% less expensive than FTTH deployment (Analysys Mason, 2008; FCC, 2010). Moreover, both deployment variants are suitable to meet the European Commission broadband target: $100 \mathrm{Mbps}$ for 50\% of the population (EC, 2010a, Guenach et al., 2011).

Fig. 1 depicts a typical copper telecommunication access network that is connected to an incumbent's central office (CO) with a fibre backbone. It can be subdivided into a feeder cable and a distribution cable network. In rural areas, the feeder cable distributes the cable to different communities and the distribution points (DP) of the distribution cable network within a community. It is subdivided into joints $(\mathrm{J})$ and forms a minimum spanning tree topology (Vidmar, Peternel, Štular, \& Kos, 2010, Dippon \& Train, 2000). That is, a connected graph of $n$ verticals and (n-1) links, which minimizes the total cable length (Christofides, 1975). Verticals and DP constitute cable consolidation points between the CO and the customer (U). Generally, these consolidation points imply shared deployment costs in the subsequent cable segment. 


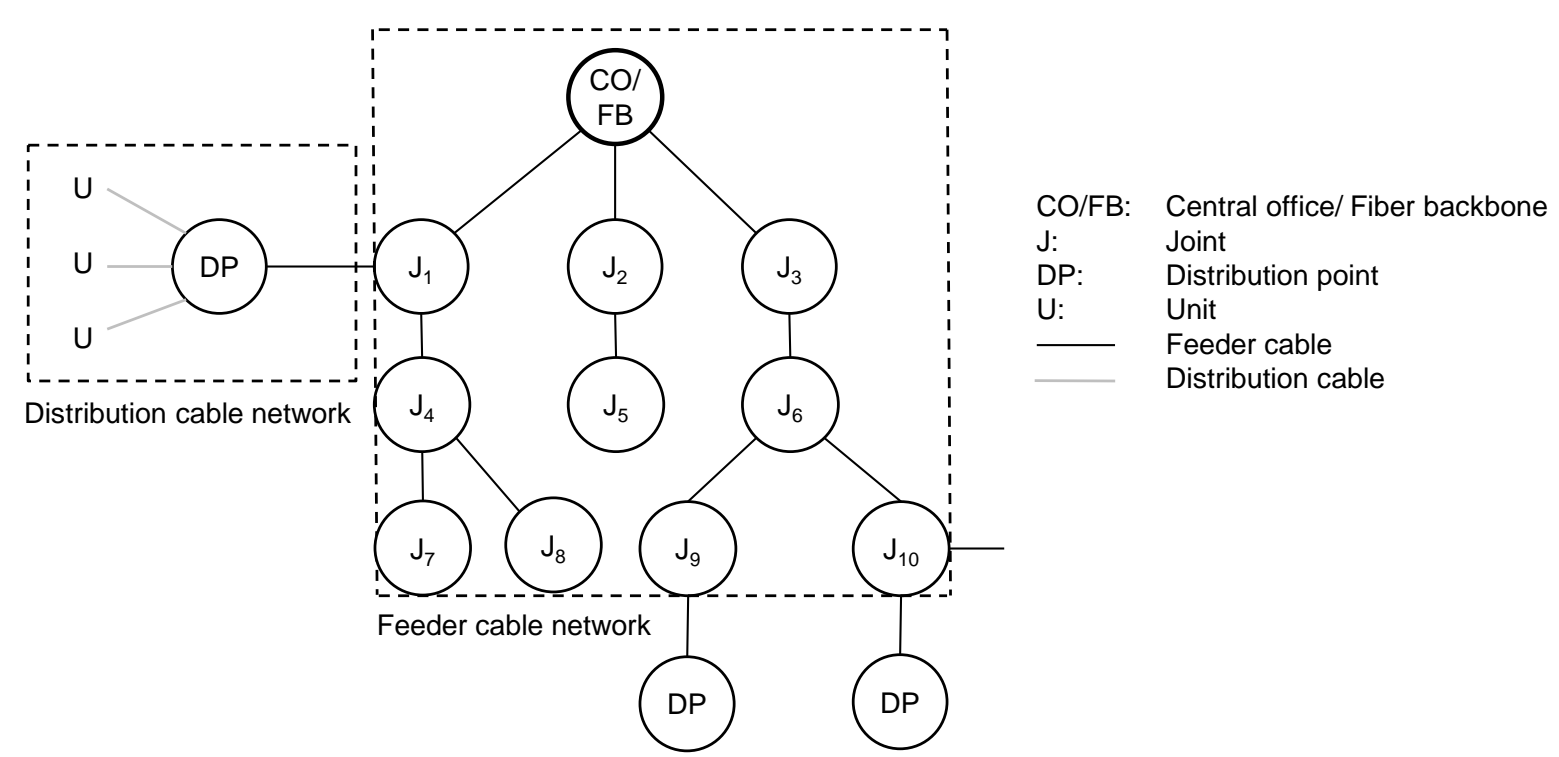

Fig. 1Typical access network topology in rural areas (adapted from Vidmar et al., 2010)

FTTC requires the replacement of copper cables in the feeder cable segment between the central office and a distribution point such as the street cabinet. Similarly, FTTB requires the replacement of the copper cable between the fibre backbone and the customer building. Generally, these cables are deployed along existing roads, as national laws in many cases allow the government to use these rights of way at no charge for the setup of public telecommunication networks. Moreover, this right can be transferred to private companies.

\subsection{The role of public authorities in rural broadband deployment}

In rural areas, average feeder cable lengths are longer and account for a higher share of total broadband deployment costs than in areas with a higher population density (Grubesic, 2008; Schneir \& Xiong, 2013). Moreover, these higher costs must be allocated to a smaller number of potential customers as in urban areas. Consequently, economic feasibility is particularly challenging if a rural community is located far away from the $\mathrm{CO}$ and encompasses few potential customers (Analysys Mason, 2008). Under these conditions, private companies may not be willing to deploy or upgrade networks within a timeframe that allows reaching national or super-national broadband goals (EC, 2010a; NBNCO, 2015). This will be referred to as market failure (EC, 2010b).

In response to market failure, public authorities across the world pursue different approaches.

Authorities in Europe have notified the European Commission (EC) about large scale state aid measures that aim to deploy fibre networks along alternative infrastructures to foster rural broadband deployment (EC, 2013a, EC 2012a, EC, 2010b). These national broadband deployment frameworks allow a community to act as a co-investor that ensures economic feasibility of otherwise unprofitable broadband projects. Typically, a local public authority defines a target area for market exploration and launching a tender. According to state aid guidelines, the authority is free to define the size of the target area. However, it should consider that a too small target area such as a single community may provide too little incentive to bid for public aid and that a too large target area may foreclose the outcome of the selection process (EC, 2013b).

Considering different economic, political and geographic preconditions other approaches to rural broadband deployment can be reasonable (Given, 2010). The Australian government has commissioned the state owned company the nextgen Group to deploy additional fibre capacities to provide competitive wholesale backbone services in regional areas. In addition, the stated owned NBN Corporation is commissioned to provide wholesale-only access network to all access seekers. The goal of this initiative is to provide download speeds of at least 50 Mbps to $90 \%$ of the fixed line premises within the constraint that public equity capital is limited 
(NBNCO, 2015). Without additional regulatory measures this approach bares the risk that fibre is deployed only to the most profitable premises in a particular target area (Given, 2010).

Both approaches exhibit an inherent risk of demand fragmentation in broadband deployment (Sawhney, 1992). This paper will provide the political and regulatory implications for reducing the risk of demand fragmentation and improving synergy utilization of alternative infrastructures.

\section{Deployment scenarios and cost modelling}

\subsection{Deployment scenarios}

It has been recognized that many states follow either FTTC or FTTB deployment strategies to reach broadband goals (Cave, 2014). Thus the relative magnitude of cost reduction effects that can be achieved by leveraging synergies with alternative infrastructures is explored in this paper for both fibre deployment variants. However, the political and regulatory implications which are presented in Section 6 do also apply to other fibre deployment variants like for example FTTP or FTTN which is being discussed for rural broadband deployment in Australia (NBNCO, 2015).

Subsequently, FTTC refers to the deployment of VDSL2 vectoring technology, which is capable of providing download speeds of up to $100 \mathrm{Mbps}$ (Guenach et al., 2011). The required street cabinets are deployed within close proximity to the customer and host active equipment. It is assumed that required power grid access is available in every community.

The FTTB deployment scenario refers to a point to multipoint 10 Gbps passive optical network (XG-PON), which is capable of providing minimum download speeds of $312 \mathrm{Mbps}$ if a splitting factor of 1:32 is used (Schneir \& Xiong, 2013). This scenario assumes that electrical power is provided from the customer building.

The analysis focuses on rural communities that do not host a CO because in such a case households can receive broadband services directly from the $\mathrm{CO}$ without additional fibre investments (Grubesic, 2008). Based on J ay et al. (2014), the term rural will be used to refer to communities with a potential customer density of 130 or less inhabitants per square kilometre. Moreover, it is assumed that one operator will upgrade a legacy copper access network in a given target area and that synergies with alternative infrastructures will be used if they are available.

In the base case, infrastructure is deployed to all customers in a target area. Moreover, the base case assumes equally distributed spare duct availabilities for a specific target area. Furthermore, backbone and co-location costs for alternative infrastructures and the CO are assumed to be at comparable costs in a competitive market (Schäfer \& Schöbel, 2005).

These assumptions are optimistic for several reasons. Depending on country specific preconditions, cable and wireless networks can be important alternative rural access technology (OECD, 2009). To address this aspect, optimized topologies will also be calculated for $50 \%, 75 \%, 90 \%$ and $95 \%$ deployment scenarios. Spare duct availability is likely to be higher along the pathway of the incumbent copper feeder cable topology. Thus, the effect of lower spare duct availability will be assessed for the feeder cable topology that originates at the alternative infrastructure. Finally, depending on market and regulatory preconditions, costs for backbone, co-location and metro aggregation networks could be either higher or lower than the incumbent offer. These aspects will be addressed with a sensitivity analysis.

\subsection{Cost modelling}

Infrastructure costs have been derived from reviews of current literature on access network cost modelling and triangulated with publicly available information. Table 1 summarizes the input values for FTTC and FTTB cost calculations. 


\begin{tabular}{lll}
\hline Item & $\begin{array}{l}\text { FTTC } \\
\boldsymbol{€}\end{array}$ & $\begin{array}{l}\text { FTTB } \\
\boldsymbol{€}\end{array}$ \\
\hline Fiber cable/m & 1 & 1 \\
Street cabinet & 13,000 & $/$ \\
Manhole & $/$ & 850 \\
Y-Branch & $/$ & 29 \\
\hline
\end{tabular}

Table 1CAPEX for infrastructure elements

The FTTC scenario requires the deployment of new street cabinets that can host vectoring cards and other active equipment. In the FTTB scenario, manholes are deployed at every road intersection within a community, and y-branch units are used to separate the individual drop cable from the distribution cable. Both scenarios assume an average fibre cable price of $1 € / \mathrm{m}$.

Depending on the density of potential customers in rural areas, different shares and costs of installation methods will be assumed to account for the possibility of duct reuse, aerial deployment and decreasing surface restoration costs. The input parameters are provided in Table 2.

\begin{tabular}{|c|c|c|c|c|c|c|}
\hline \multicolumn{7}{|l|}{ Installation costs } \\
\hline \multirow{2}{*}{$\begin{array}{l}\text { Potential number } \\
\text { of customers per } \\
\mathbf{k m}^{2}\end{array}$} & \multicolumn{2}{|c|}{ Aerial } & \multicolumn{2}{|c|}{ Digging } & \multicolumn{2}{|c|}{$\begin{array}{c}\text { Duct } \\
\text { reuse }\end{array}$} \\
\hline & $\%$ & $\epsilon / \mathbf{m}$ & $\%$ & $€ / \mathbf{m}$ & $\%$ & $€ / \mathbf{m}$ \\
\hline $130 \geq x>75$ & 0 & 15 & 80 & 60 & 20 & 2 \\
\hline $75 \geq x>30$ & 5 & 15 & 85 & 55 & 10 & 2 \\
\hline $30 \geq x>15$ & 10 & 15 & 85 & 50 & 5 & 2 \\
\hline$<15$ & 15 & 15 & 85 & 45 & 0 & 2 \\
\hline
\end{tabular}

Table 2 Infrastructure installation methods

Following common practice, OPEX is considered as a mark-up on the modelled passive (1\%) and active equipment (5\%) (J ay et al., 2014; Schneir \& Xiong, 2013). Moreover, metro aggregation, backbone and co-location costs are modelled as OPEX. In this sense, the monthly cost of $3.66 €$ per customer is derived from a market analysis that has been conducted by the German regulator (Bundesnetzagentur, 2013). OPEX costs rise with the number of customers. Therefore, for the first three years OPEX calculations consider a take-up of 25\%, 50\% and 70\% (Schneir \&Xiong, 2013). Equal customer acquisition and customer churn rates are assumed to keep this take-up rate constant for the remaining years of the investment timeframe (Schneir \&Xiong, 2013). It is assumed that networks are rolled out in equal portions over the first three years of a 10 year investment timeframe. Moreover, costs are compared on a cumulative present value basis assuming a yearly discount rate of $10 \%$.

This model does not consider retail, service provisioning or customer equipment cost. Moreover, it does not consider price declines of equipment.

\section{Synergy evaluation model}

\subsection{Data and sources}

The subsequent assessment is based on map data provided by OSM, which is an open-source, free-of-charge digital map of the world. OSM data are crowd-sourced from a growing community of volunteers that has contributed to a high data density and quality in terms of completeness and accuracy comparable to geodata from commercial providers (Girres \& Touya, 2010; Haklay, 2010; Neis, Zielstra, Zipf, \& Strunk, 2010; Zielstra \& Zipf, 2010). The highest levels of data density, i.e., number of nodes and ways per area, can be found in the 
countries of central Europe (OpenStreetMap, 2012). In the case of Germany, the total OSM street network even exceeds the information in commercial data sets by 27\% (Neis et al., 2010).

The model is applied to OSM data from Germany that hold the locations of all German central offices, more than 11,000 municipalities and cities, 368,745 geodata points (GP) of the highway network, 870,831 GP of the railroad network, 184,031 GP of the power line network and 26,228 GP of the pipeline network. In addition, the complete OSM street network is incorporated in the analysis. The use of described data has been accompanied by numerous validations in satellite pictures and other public data sources. The OSM data are merged with demographic data provided by the German census to consider municipal information on the number of households and population density. Table 3 provides an overview of the model data and sources.

\begin{tabular}{|c|c|c|c|}
\hline Information & Description & $\begin{array}{l}\text { Derived model } \\
\text { characteristics }\end{array}$ & Data source \\
\hline \multicolumn{4}{|c|}{ Feeder cable model } \\
\hline Central offices & $\begin{array}{l}\text { Locations of all central } \\
\text { offices in Germany }\end{array}$ & $\begin{array}{l}\text { Distance of CO to } \\
\text { communities in rural } \\
\text { areas }\end{array}$ & $\begin{array}{l}\text { (OpenStreetMap, } \\
\text { 2013) }\end{array}$ \\
\hline Main roads & $\begin{array}{l}\text { Length of main roads of } \\
\text { a community }\end{array}$ & $\begin{array}{l}\text { Required feeder cable } \\
\text { trench length for FTTB } \\
\text { and FTTC }\end{array}$ & $\begin{array}{l}\text { (OpenStreetMap, } \\
\text { 2013) }\end{array}$ \\
\hline $\begin{array}{l}\text { Location } \\
\text { centers }\end{array}$ & $\begin{array}{l}\text { Center of a rural } \\
\text { community }\end{array}$ & $\begin{array}{l}\text { Approximated } \\
\text { termination point of } \\
\text { the feeder cable }\end{array}$ & $\begin{array}{l}\text { German census } \\
\text { bureau } \\
\text { (Regionaldatenbank, } \\
\text { 2013) }\end{array}$ \\
\hline $\begin{array}{l}\text { Alternative } \\
\text { infrastructures }\end{array}$ & $\begin{array}{l}\text { Coordinates of } \\
\text { railroads, highways, } \\
\text { electricity networks and } \\
\text { pipeline }\end{array}$ & $\begin{array}{l}\text { Distance from next } \\
\text { railroad, highway, } \\
\text { major electricity } \\
\text { network or pipeline to } \\
\text { community center in } \\
\text { rural community }\end{array}$ & $\begin{array}{l}\text { (OpenStreetMap, } \\
\text { 2013) }\end{array}$ \\
\hline \multicolumn{4}{|c|}{ Distribution cable model } \\
\hline $\begin{array}{l}\text { Demographic } \\
\text { data }\end{array}$ & $\begin{array}{l}\text { Households per } \\
\text { community, population } \\
\text { density, number of } \\
\text { buildings per } \\
\text { community, } \\
\text { community center }\end{array}$ & $\begin{array}{l}\text { Calculation of required } \\
\text { deployment meters } \\
\text { per household }\end{array}$ & $\begin{array}{l}\text { German census } \\
\text { bureau } \\
\text { (Regionaldatenbank, } \\
\text { 2013) }\end{array}$ \\
\hline $\begin{array}{l}\text { Residential } \\
\text { roads }\end{array}$ & $\begin{array}{l}\text { Aggregated length of all } \\
\text { residential roads in a } \\
\text { rural community }\end{array}$ & $\begin{array}{l}\text { Approximation of } \\
\text { required distribution } \\
\text { cable trench length for } \\
\text { FTTB }\end{array}$ & $\begin{array}{l}\text { (OpenStreetMap, } \\
\text { 2013) }\end{array}$ \\
\hline
\end{tabular}

Table 3 Modelling data and sources

\subsection{Internet access model}

This section describes an internet access model, which assesses the required access network deployment costs per rural households, if savings through the usage of alternative backbone infrastructures are considered. The model is subdivided into a feeder cable and a distribution cable model. 


\subsubsection{Feeder cable model}

Thefeeder cable model calculates the required trench length between a rural community centre and a fibre backbone interconnection point. In contrast to related literature on broadband access models, (Analysys Mason, 2008; Lannoo et al., 2008; Vidmar et al., 2010), this fibre backbone interconnection point does not necessarily have to be the incumbent's central office. Instead, the model also considers potential backbone interconnections at the next railroad, highway, major electricity network or pipeline.

In the first step, airline distance calculations between all German community centres and the corresponding next alternative infrastructure are conducted on a national level to identify one national infrastructure that exhibits a particularly low average distance to rural communities.

In the second step, a trench-length-optimized feeder cable is calculated considering the most promising alternative infrastructure and the incumbent's central offices. This step is based on graph theory and takes advantage of the fact that telecommunication access networks are usually planned as a minimum spanning tree with the fibre backbone interconnection at its root (Vidmar et al., 2010). A minimum spanning tree can be calculated with the wellunderstood Kruskal's algorithm (Kruskal, 1956). Table 4 indicates how this algorithm is adjusted to provide one spanning tree that originates at the $\mathrm{CO}$ and an additional one that originates at the alternative infrastructure.

Input: Edges $\mathrm{E}$ containing all distances between the $\mathrm{CO}$, communities and alternative infrastructure interconnection points,

Set S_CO containing the CO,

Set S_Infra containing all alternative infrastructure interconnection points;

Output: Minimum Spanning Trees T_CO and T_Infra;

(1) Add temporary 0 -weigth edges between $\mathrm{S}_{-} \mathrm{CO}$ and every element of S_Infra to E;

(2) Edges E2 = Edges of Kruskal_Algorithm(E) with weight $>0$;

(3) While(E2 is not empty)

Foreach edge $(\mathrm{v}, \mathrm{w})$ from $\mathrm{E} 2$

If( $\mathrm{v}$ or $\left.\mathrm{w} \in \mathrm{S}_{-} \mathrm{CO}\right)$

Add $(\mathrm{v}, \mathrm{w})$ to T_CO;

Add v and w to S_CO;

Remove $(v, w)$ from $E 2$;

Else If(v or $w \in S_{-}$Infra)

Add $(\mathrm{v}, \mathrm{w})$ to $\mathrm{T}$ Infra;

Add $\mathrm{v}$ and $\mathrm{w}$ to S_Infra;

Remove $(v, w)$ from E2;

Table 4 Synergy evaluation algorithm

The algorithm's input requires the location of the $\mathrm{CO}$, alternative infrastructure interconnection points and the distances between those locations. Alternative infrastructure interconnection points are located at an intersection between a public road and the alternative infrastructure. Distances between the two locations v and w are calculated by using the route- 
planning capability of OSM. They are referred to as edges and have a weight that is equivalent to the distance between $\mathrm{v}$ and $\mathrm{w}$.

The first step of the algorithm adds 0 -weight edges between all potential fibre backbone locations. This ensures that the standard Kruskal's algorithm can be used to calculate a single minimum spanning tree that minimizes the length of the total network topology, in the second step. In the third step all weighted edges of the previously calculated spanning tree are iteratively sorted to one of two spanning trees that either originates at the $\mathrm{CO}$ ( $\left.\mathrm{T}_{-} \mathrm{CO}\right)$ or the alternative infrastructure ( $T_{-}$Infra).

The final feeder cable topology serves all communities that have previously been served by a $\mathrm{CO}$. If the total feeder cable length is smaller than the feeder cable length of the minimum spanning tree that serves all communities from the $\mathrm{CO}$, this difference will be referred to as feeder cable savings potential.

\subsubsection{Distribution cable model}

The distribution cable model considers a FTTC and a FTTB fibre deployment scenario, and relates the financial savings from an optimized feeder cable topology to the total costs of broadband deployment. The FTTC distribution cable network model is based on the assumption that all households of a particular community are already served with a copperwire cable for purposes of wire-line telephony and internet services, which provide less than $30 \mathrm{Mbps}$. To achieve customer download speeds close to $100 \mathrm{Mbps}$ it is assumed that street cabinets with vectoring technology are deployed within a distance of $1,000 \mathrm{~m}$ along the residential streets of a rural community (Guenach et al., 2011). This results in a maximum distance of $500 \mathrm{~m}$ to the customer premises. As indicated in Eq. (1) the number of street cabinets $\mathrm{c}$ is inferred from a community's aggregated residential street length $\mathrm{r}$. It is assumed that one additional cabinet is deployed if the aggregated street length is smaller than $1,000 \mathrm{~m}$.

$$
c(r)=\left\{\begin{array}{cc}
1 & r<1,000 \\
\left\lceil\frac{r}{1,000}\right\rceil & r \geq 1,000
\end{array}\right.
$$

Accordingly, as described in Section 2.1, the additional trench length d between the cabinets is calculated with the subsequent Eq. (2):

$$
d=1,000 *(c-1)
$$

The FTTB deployment scenario is based on a street-length aware broadband deployment model proposed by Lannoo et al. (2008). It is used to calculate the trench and fibre length required in addition to the FTTC deployment scenario. The initial model has been developed for the city of Ghent and assumes that trenches and fibre cables are required along both sides of a residential street. To adjust the model to rural distribution networks it is assumed that this percentage decreases with population density according to Table 5. 


\begin{tabular}{ll}
\hline $\begin{array}{l}\text { Potential number of } \\
\text { customers per } \mathbf{k m}^{2}\end{array}$ & $\begin{array}{l}\text { Share of trenches along } \\
\text { both sides of a residential } \\
\text { road }\end{array}$ \\
\hline $130 \geq \mathrm{x}>75$ & 90 \\
$75 \geq \mathrm{x}>30$ & 75 \\
$30 \geq \mathrm{x}>15$ & 50 \\
$<15$ & 35 \\
\hline
\end{tabular}

Table 5 Required trenches along roads

Following Lannoo et al. (2008), trench and fibre length are calculated separately. The additional fibre cable length which is required in a FTTB scenario is derived from the routing distance between the street cabinet and a customer premises of a rural community. For the defined distance between street cabinets this results in an average cable length of $250 \mathrm{~m}$. Furthermore, it is assumed that buildings are located in the middle of a customer premises. The analysis of German census bureau data on average rural premises sizes and cuts results in a mark-up of $17 \mathrm{~m}$ for connecting the building with the distribution point at the street (Regionaldatenbank, 2013).

\section{Results}

This section presents the results of the synergy evaluation model in two steps. First, an overview on the data of the feeder cable analysis is provided. As illustrated in Section 4.1.1, this part of the results is derived from air-line distance calculations and comparisons. The second part of the analysis builds on trench-optimized network topologies, which are based on minimum spanning tree calculations.

\subsection{Geographic preconditions for synergy utilization}

Table 6 presents the percentage of communities and associated potential customers according to the proximity to the closest potential fibre backbone.

\begin{tabular}{|c|c|c|c|c|c|c|c|c|c|c|}
\hline \multirow[b]{3}{*}{$\begin{array}{l}\text { Air-line } \\
\text { proximity } \\
\text { (m) }\end{array}$} & \multicolumn{10}{|c|}{ Nearest infrastructure to rural community center } \\
\hline & \multicolumn{2}{|c|}{$\mathbf{C O}$} & \multicolumn{2}{|c|}{ Railroads } & \multicolumn{2}{|c|}{ Power lines } & \multicolumn{2}{|c|}{ Highways } & \multicolumn{2}{|c|}{ Pipeline } \\
\hline & $\begin{array}{c}\text { com. } \\
\text { (\%) }\end{array}$ & $\begin{array}{l}\text { pot. } \\
\text { cust. } \\
\text { (\%) }\end{array}$ & $\begin{array}{c}\text { com. } \\
\text { (\%) }\end{array}$ & $\begin{array}{l}\text { pot. } \\
\text { cust. } \\
\text { (\%) }\end{array}$ & $\begin{array}{c}\text { com. } \\
\text { (\%) }\end{array}$ & $\begin{array}{l}\text { pot. } \\
\text { cust. } \\
\text { (\%) }\end{array}$ & $\begin{array}{c}\text { com. } \\
\text { (\%) }\end{array}$ & $\begin{array}{l}\text { pot. } \\
\text { cust. } \\
\text { (\%) }\end{array}$ & $\begin{array}{c}\text { com. } \\
\text { (\%) }\end{array}$ & $\begin{array}{l}\text { pot. } \\
\text { cust. } \\
\text { (\%) }\end{array}$ \\
\hline 1,000 & 11.4 & 11.7 & 18.6 & 26.7 & 6.7 & 8.5 & 3.9 & 4.2 & 1.0 & 1.3 \\
\hline 3,000 & 18.5 & 21.6 & 11.3 & 11.4 & 5.4 & 3.9 & 3.9 & 2.8 & 0.7 & 0.8 \\
\hline 5,000 & 11.0 & 4.6 & 3.7 & 1.4 & 1.1 & 0.4 & 0.7 & 0.2 & 0.3 & 0.1 \\
\hline 7,000 & 1.5 & 0.4 & 0.3 & 0.1 & 0.0 & 0.0 & 0.0 & 0.0 & 0.0 & 0.0 \\
\hline$>7,000$ & 0.1 & 0.0 & 0.0 & 0.0 & 0.0 & 0.0 & 0.0 & 0.0 & 0.0 & 0.0 \\
\hline Total & 42.4 & 38.3 & 33.9 & 39.5 & 13.2 & 12.8 & 8.4 & 7.3 & 2.1 & 2.2 \\
\hline
\end{tabular}

Table 6 Geographic proximity of rural communities to potential fibre backbones

The table indicates that $42.4 \%$ of the rural communities (com.) in Germany are situated closer to the central office than to an alternative infrastructure. Of those communities, $11.4 \%$ are located within an airline proximity of $1,000 \mathrm{~m}$ or below. Another $18.5 \%$ of the communities are located within a proximity above 1,000 and below or equal to $3,000 \mathrm{~m}$. Though at least $33.9 \%$ of the rural communities are situated closer to railroads than to a central office those communities host at least $39.5 \%$ of the potential customers (pot. cust.). This value is slightly higher than the number of potential customers in close proximity to the central office. For 
another $23.7 \%$ of the rural communities, other alternative infrastructures are closer to the community centre than to COs or railroads.

A single community within a close proximity to an alternative infrastructure will usually not justify a broadband deployment project. Consequently, it is of importance to assess the clustering degree of rural communities with a close proximity to an alternative infrastructure. Fig. 2 addresses this aspect on a federal, state and county level. It depicts the percentage of communities with a close proximity to an alternative infrastructure within a county for three synergy density categories. Counties that exhibit less than 33\% rural communities that are located closer to an alternative infrastructure than to the $\mathrm{CO}$ are assigned to a low synergy density category. Similarly, counties which exhibit more than $66 \%$ rural communities that are located closer to an alternative infrastructure than to the CO are assigned to a high synergy density category. The remaining counties are assigned to an intermediate category.

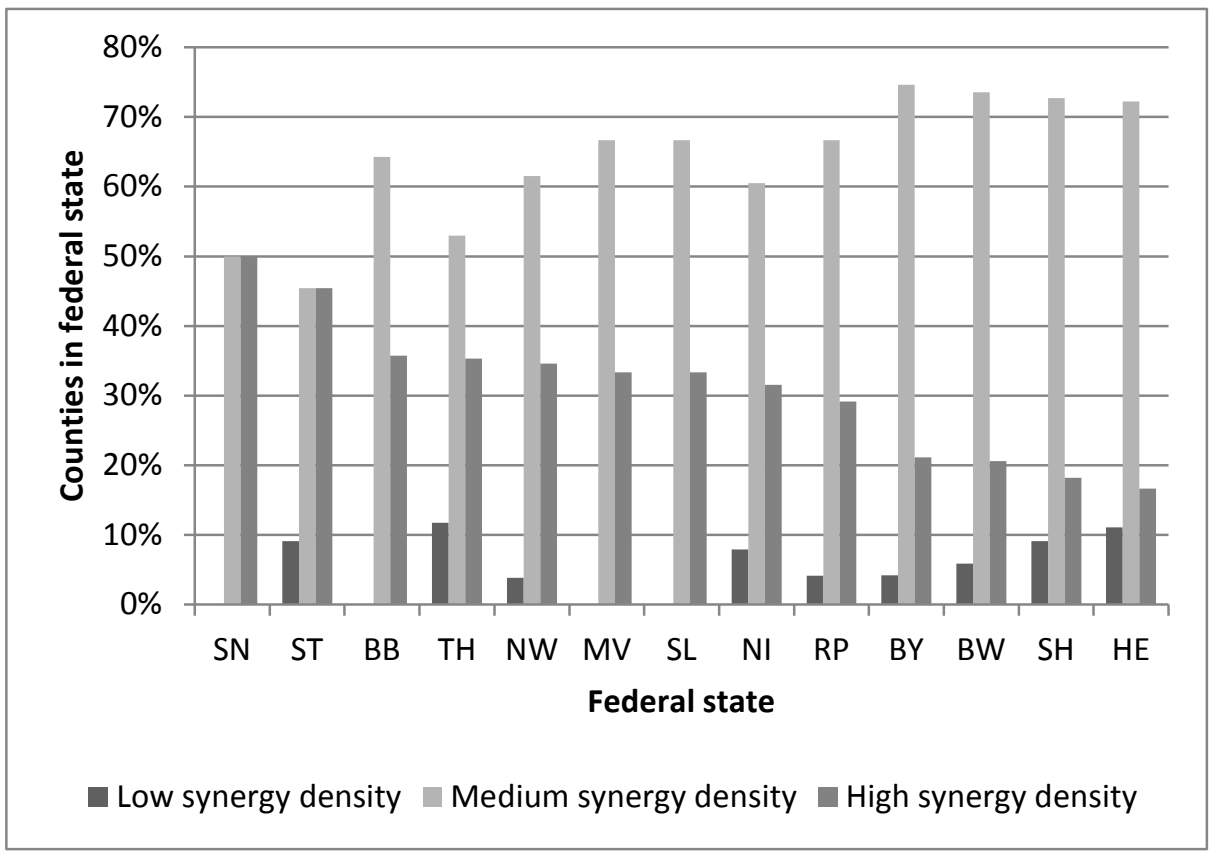

Fig. 2 Density of rural communities with close proximity to alternative infrastructures

Fig. 2 shows that the density of rural communities with a closer proximity to alternative infrastructures as opposed to the CO differs by county and federal state. The majority of German counties exhibit a medium synergy density. For 2 of 13 states the number of counties with a high synergy density equals the number of counties in the intermediate density category. Only a small share of the federal states exhibits a low synergy density.

\subsection{Characteristics of the optimized feeder cable topology}

Based on the findings of Table 6 , the subsequent analyses focus on assessing synergies that stem from the railroad network. For this purpose every rural community of a county is allocated to a minimum spanning tree that either starts at the central office or at a railroad. Table 7 provides descriptive statistical figures of the resulting spanning trees.

\begin{tabular}{lcc}
\hline & Railroad spanning tree & CO spanning tree \\
\hline Avg \# of communities & 2.25 & 2.07 \\
SD \# of communities & 1.88 & 1.94 \\
Avg \# of pot. Customers & 1,518 & 1,281 \\
SD \# of customers & 1,313 & 1,573 \\
\hline
\end{tabular}

Table 7 Minimum spanning tree analysis for optimized feeder cable topology 
Table 7 shows that an optimized feeder cable topology results in spanning trees that connect 2 communities per railroad and per CO spanning tree on average. The average number of customers reachable from a potential railroad spanning tree is slightly higher than in the CO spanning tree. The rather high standard deviation (SD) for the number of communities and customers that are served in a minimum spanning tree indicates that a variety of rural spanning tree topologies exist.

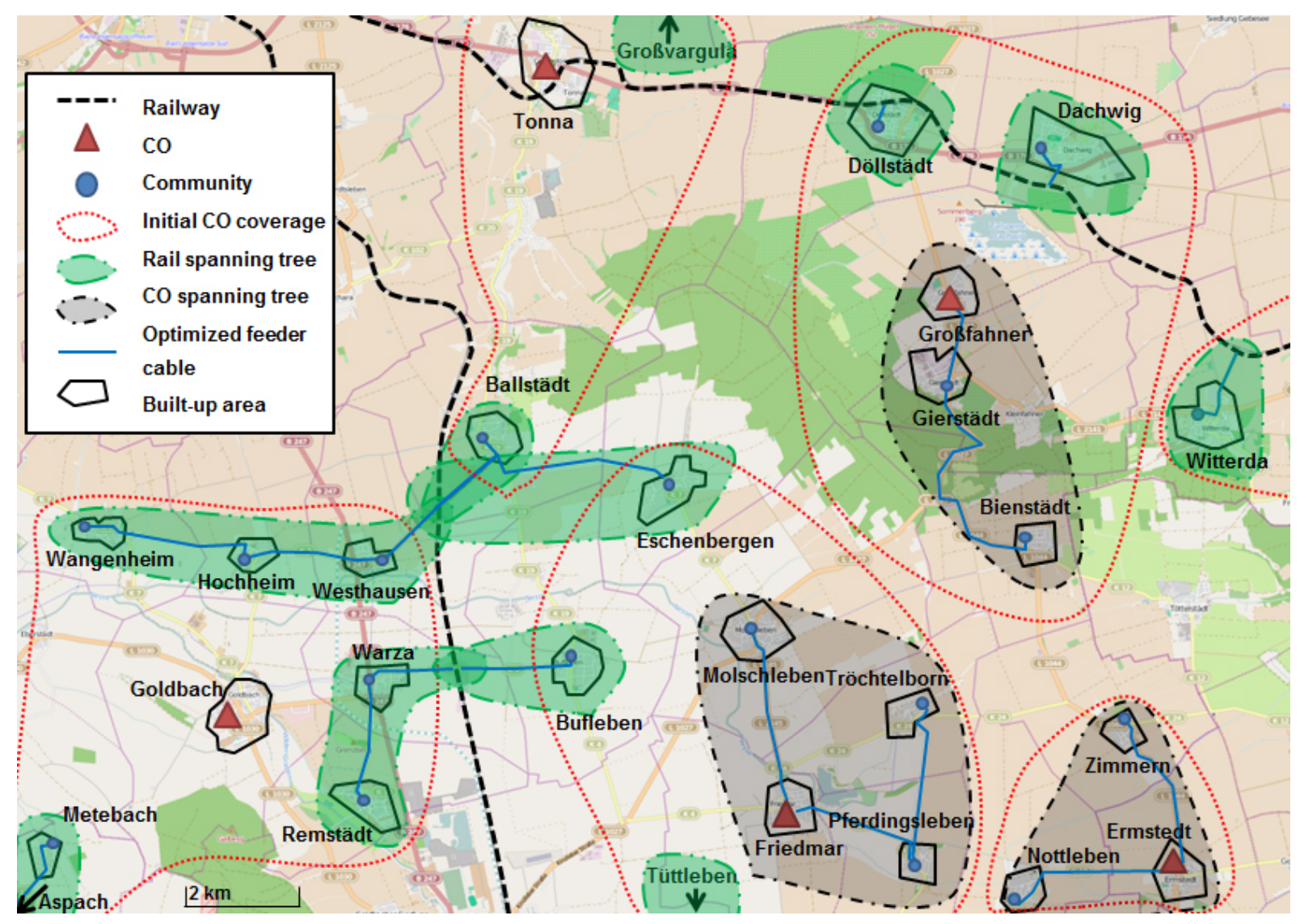

Fig. 3 Optimized rural feeder cable topology in Thuringia (Germany)

Fig. 3 depicts an optimized feeder cable topology in a typical rural area in the German federal state Thuringia (TH). Communities such as Ballstädt, Bufleben or Eschenbergen exhibit a street routing distance of more than $6,000 \mathrm{~m}$ to the next CO. In contrast, potential feeder cable lengths to the next railroad fibre connection are up to six times shorter. Thus, in an optimized topology they are associated with a railroad spanning tree. Communities such as Nottleben or Zimmern exhibit a long routing distance to railroads and are assigned to a CO spanning tree.

Using its widely available fibre capacities along railroads, the German company Arcor has deployed VDSL with download speeds of up to $50 \mathrm{Mbps}$ in Ballstädt and announced a national roll-out (Briegleb, 2008). After the acquisition of Arcor by Vodafone these capacities have primarily been used for the deployment of the wireless technology LTE which requires less CAPEX per connected customer than FTTC and currently provides average rural down-load speeds of approximately $10 \mathrm{Mbps}$ (Pages \&Pe, 2013).

\subsection{Cost advantages of alternative infrastructures}

In this section, cost advantages of alternative infrastructures are explored in two steps. First, savings of an optimized feeder cable topology are put in perspective to the total costs of FTTC and FTTB deployment. Thereafter, a sensitivity analysis explores the effects of parameter variations on possible cost reductions.

Fig. 4 depicts the FTTC and FTTB investment per customer, which is required for connecting $50 \%, 75 \%, 90 \%, 95 \%$ or $100 \%$ of all households in a county with optimized feeder cable 
topologies. Moreover, an alternative connection via the $\mathrm{CO}$ is depicted for both fibre deployment variants. For determining the shares of connected households, communities have been ordered by a decreasing number of households. That is, communities with the lowest number of households within a county will only be connected in the $100 \%$ deployment scenario.

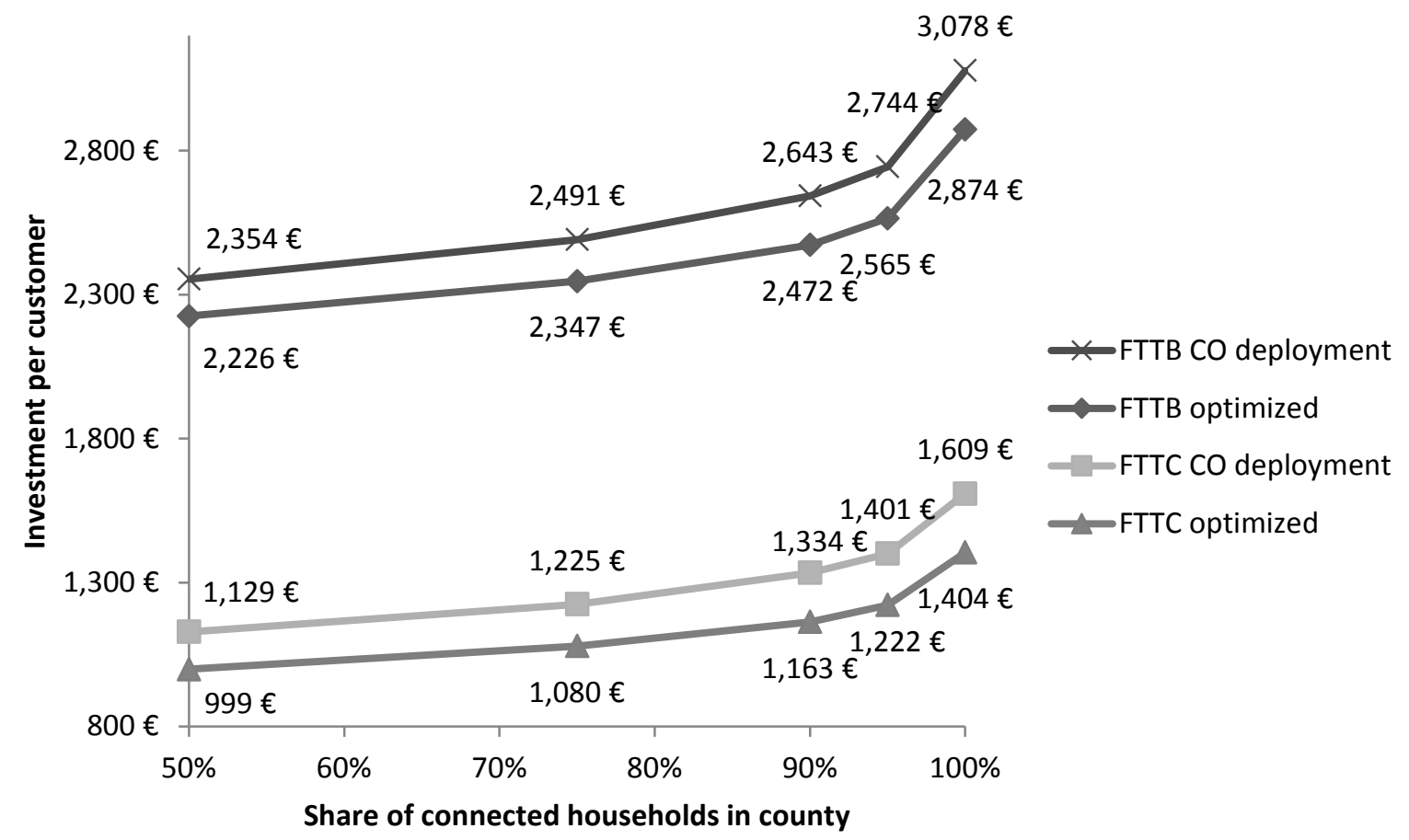

Fig. 4 Financial impact of synergy utilization with railroads

Results indicate that in the base case absolute savings per customer vary between $205 €$ in the $100 \%$ deployment case and $128 €$ in the $50 \%$ deployment case. This results in a maximum relative savings potential of $13 \%$ for the FTTC case and $7 \%$ for the FTTB case. However, as noted in Section 3.1 variations in the monthly metro-aggregation, backbone, co-location costs and general spare duct availability can impact the magnitude of these savings. Thus, a sensitivity analysis is exploring these effects in Table 8. In this analysis, parameters for the CO deployment are kept constant while parameters of the alternative infrastructure topology are subject to parameter variations.

\begin{tabular}{|c|c|c|c|c|c|}
\hline \multirow[b]{2}{*}{ Parameter } & \multirow[b]{2}{*}{$\begin{array}{l}\text { Variati } \\
\text { on }(\%)\end{array}$} & \multicolumn{2}{|l|}{ FTTC } & \multicolumn{2}{|l|}{ FTTB } \\
\hline & & $\begin{array}{l}\text { Optim } \\
\text { ized } \\
(€)\end{array}$ & $\begin{array}{l}\text { Difference to } \\
\text { CO } \\
\text { deployment } \\
\text { (\%) } \\
\end{array}$ & $\begin{array}{l}\text { Optimiz } \\
\text { ed }(€)\end{array}$ & $\begin{array}{l}\text { Difference to } \\
\text { CO } \\
\text { deployment } \\
\text { (\%) }\end{array}$ \\
\hline \multirow{2}{*}{$\begin{array}{l}\text { Monthly metro-aggregation, } \\
\text { backbone and co-location costs }\end{array}$} & +50 & 1,213 & 1 & 2,480 & 1 \\
\hline & -50 & 946 & 23 & 2,213 & 11 \\
\hline \multirow{2}{*}{$\begin{array}{l}\text { Spare duct availability in feeder } \\
\text { cable topology }\end{array}$} & -50 & 1,088 & 11 & 2,356 & 5 \\
\hline & $\begin{array}{l}-\quad 100 \\
\end{array}$ & 1,097 & 11 & 2,364 & 5 \\
\hline
\end{tabular}

Table 8 Sensitivity analysis for deployment to $75 \%$ of all households

Results show that a variation of the monthly metro-aggregation, backbone and co-location costs per customer have a strong impact on the relative cost advantages. If these costs are approximately $50 \%$ higher than the incumbent's offer, the savings potential of alternative infra-structure use is close to zero. In contrast, $50 \%$ lower monthly costs can increase the savings potential to $23 \%$ in the FTTC case and $11 \%$ in the FTTB case. A lower share of spare 
ducts in the alternative infrastructure feeder cable topology hardly reduces relative cost savings. This is due to three reasons. First, as noted in Section 3.2, general spare ducts availability in rural areas is usually much lower than in more densely populated areas. Second, an increase of feeder cable deployment costs is allocated to all households of a connected community. Finally, spare duct availability in the distribution cable segment is not affected by an optimized feeder cable topology.

\subsection{Comparison with other studies}

As of today, few national broadband deployment cost models have explored synergy optimized feeder cable topologies. Moreover, most existing cost models are not based on a street-length aware modelling approach that can account for the variety of rural cable topologies (cf. Table 7). Nevertheless, Fig. 4 indicates that the investment costs per potential customer without synergy utilization align well with existing cost modelling studies. This study has identified FTTB investment costs of 3,078 € per potential customer in rural areas. Based on averaged real world cable length from several European operators, Schneir and Xiong (2013) calculate costs of 3,250 € per rural home connected for a single operator with a market share of $70 \%$. For the FTTC deployment scenario this model indicates investment costs without synergy utilization of 1,609 $€$ per potential customer. Analysys Mason (2008) takes into account the costs of customer premises equipment and identified costs of 1,690 $€$ for the most remote geotype at a market share of $70 \%$.

\section{Political and regulatory implications}

The presented results indicate that cost savings can be achieved if alternative national infrastructures are considered as source for broadband networks in rural areas. As a consequence this paper contributes to current efforts to maximize synergy utilization across networks and reduce the civil engineering costs of broadband deployment (EC, 2013c, NBNCO, 2015). However, the efficient use of those infrastructures depends on appropriate political and regulatory incentive structures.

Section 5.1 shows that geographic preconditions for synergy utilization can differ largely between federal states and counties. Thus, political and regulatory efforts directed at improving efficiency gains across national networks should be focused on geographic areas with favourable preconditions for synergy utilization. Under disadvantageous geographic preconditions for synergy utilization, incumbent COs are more likely to be an essential facility for co-location. If competition in the local-loop usage is desired, the regulator should ensure the availability of co-location options as the incumbent is migrating to fibre access networks and closing down facilities. In countries like Australia the physical network is provided by a national company. In this case regulation needs to ensure through periodic wholesale price rebalancing and regulatory measures in the utility sector that the national company maximizes synergy utilization across physical networks.

Section 5.2 shows that an optimized feeder cable topology is connecting up to five communities with every fibre backbone connection. Thus, local authority practice of starting separate tenders and market explorations for neighbouring communities results in artificial demand fragmentation (Sawhney, 1992; BBB, 2014). To improve the use of alternative infrastructures, tenders should be started and coordinated at a county or federal state level. At this level, companies should be allowed to bid for lots within the target area.

The presented cost analysis in Section 5.3 highlights the importance of variations in the monthly metro-aggregation, backbone and co-location costs for the efficient use of alternative infrastructures. Especially if owners of alternative infrastructures have been obligated to offer fibre or spare ducts capacities, these costs could be set prohibitively high. If necessary, national regulatory measures should ensure that the cost of using alternative infrastructure capacities does not exceed the incumbent's offer by more than $50 \%$. 


\section{Conclusion}

To address the economic challenges associated with rural broadband deployment, public aid and cost reduction measures will be required. This paper has used a street-aware synergy evaluation model to assess the financial magnitude of cost savings that can be achieved if national alternative infrastructures are considered as source for broadband networks in rural areas. As such, it proposes an IS pilot instrument to guide political and regulatory decisions.

Analyses suggest that an optimized feeder cable topology can reduce the costs of rural broadband deployment if alternative infrastructure fibre backbone, metro-aggregation and colocation costs do not exceed the incumbent's offer by more than $50 \%$. To foster the deployment of cost optimized network topologies, public authorities should aggregate customer demand in large tender areas which cover multiple rural communities. Moreover, regulators need to be aware of regional differences in the preconditions for synergy utilization and should consider them as COs are closed down in the context of the migration to fibre networks.

This paper finds that railroad networks exhibit the largest national synergy potential in the case of Germany. Because densities of railroad networks differ across countries, synergy potentials may be alike. Thus, it would be worthwhile to apply the proposed model to other markets. Although corresponding OSM data are available for 69 countries in the world (OpenStreetMap, 2012) and its quality has been certified within several case studies, triangulation with other data sources should complement data usage. Further research may build on this contribution and explore related aspects. First and foremost, research should be devoted to the amount of savings that can be achieved through the reduction of COs, as the incumbent is migrating infrastructure to fibre access networks as well as geographical aspects of regulation or co-investment strategies.

\section{References}

Analysys Mason. (2008). The costs of deploying fibre-based next-generation broadband infrastructure. Final report for the Broadband Stakeholder Group. Ref: 12726-371. Available at: http:// www.analysysmason.com/ PageFiles/ 5766/ Analysys-Mason-finalreport-for-BSG-(Sept2008).pdf [Accessed 8 September 2008].

BBB. (2014). Breitband-Ausschreibungen. Available at: https:// www.breitbandausschreibungen.de/ publicOverview [Accessed 12 September 2014].

Briegleb, V. (2008) Arcor testet VDSL in Thüringer Gemeinde. Available at: http:// www.heise.de/ netze/ meldung/ Arcor-testet-VDSL-in-Thueringer-Gemeinde217119.html [Accessed 20 April 2015].

Bundesnetzagentur (2013). Genehmigung von entgelten für den zugang zur teilnehmeranschlussleitung (monatliche überlassungsentgelte). BK 3c-13/002, Bonn: Beschlusskammer 3 der Bundesnetzagentur. Available at: http:/ / beschlussdatenbank.bundesnetzagentur.de/index.php?lr=view_bk_overview\&g etfile=1\&file=5929 [Accessed $20 \mathrm{~J}$ anuary 2015].

Cave, M. (2014). The ladder of investment in Europe, in retrospect and prospect. Telecommunications Policy, in press, DOI: http://dx.doi.org/ 10.1016/j.telpol.2014.04.012.

Chatzi S., Lazaro, J . A., Prat, J ., \&Tomkos, I. (2013). A techno-economic study on the outside plant cost of current and next-generation Fiber-to-the-X deployments. Fiber and Integrated Optics, 32(1), 12-27.

Christofides, N. (1975). Graph theory: An algorithmic approach. London: Academic Press.

Dippon, C. M., \& Train, K. E. (2000). The cost of the local telecommunication network: A comparison of minimum spanning trees and the HAI model. Telecommunications Policy, 24(3), 253-262. 
European Commission (EC). (2010a). A digital agenda for Europe. Brussels: European Commission. Available at: http://eurlex.europa.eu/LexUriServ/ LexUriServ.do?uri=COM:2010:0245:FIN:EN:PDF [Accessed 6 March 2015].

European Commission (EC). (2010b). State aid N407/ 2009 - Spain - Optical fibre Catalonia (Xarxa Oberta). Brussels: European Commission. Available at: http:// ec.europa.eu/competition/ state_aid/ cases/232264/232264_1132944_78_1.pdf [Accessed 6 March 2015].

European Commission (EC). (2012a). Stateaid SA.34732 (2012/ N) - Italy - Bulgas - Fibersar - NGA Sardegna. Brussels: European Commission. Available at: http:// ec.europa.eu/competition/ state_aid/ cases/244582/244582_1390156_60_2.pd f [Accessed 30 March 2015].

European Commission (EC). (2012b). Support for the preparation of an impact assessment to accompany an EU initiative on reducing the cost of high-speed broadband infrastructure deployment. Luxembourg: The Publications Office of the European Union. Available at: http:// ec.europa.eu/information_society/newsroom/ cf/dae/document.cfm?doc_id=18 77 [Accessed 2 February 2015].

European Commission (EC). (2013a). State aid SA.33656 (2012/NN) - Ireland - Next generation (backhaul) network (NGN) alongside a gas pipeline in Galway and Mayo. Brussels: European Commission. Available at: http:// ec.europa.eu/competition/ state_aid/ cases/243213/243213_1504550_221_2.pd f [Accessed 12 March 2015].

European Commission (EC). (2013b). EU guidelines for the application of state aid rules in relation to the rapid deployment of broadband networks. Available at: http:// eurlex.europa.eu/LexUriServ/ LexUriServ.do?uri=OJ :C:2013:025:0001:0026:EN:PDF [Accessed 23J anuary 2015].

European Commission (EC). (2013c). Regulation of the European Parliament and of the council on measures to reduce the cost of deploying high-speed electronic communications networks (2013/0080). Available at: http://eurlex.europa.eu/ LexUriServ/ LexUriServ.do?uri=COM:2013:0147:FIN:EN:PDF [Accessed 4 March 2015].

Falch, M., \& Henten, A. (2010). Public private partnerships as a tool for stimulating investments in broadband. Telecommunications Policy, 34(9), 496-504.

Federal Communications Office (FCC). (2010). Connecting America: The National Broadband Plan. 125-136. Washington, DC: U.S. Government Printing Office. Available at: $\quad$ http:// www.umic.pt/images/ stories/ publicacoes5/ national-broadband-plan.pdf [Accessed 5J une 2014].

FTTH Council Europe. (2013). Annual report April 2012 - April 2013. Available at: http:// www.ftthcouncil.eu/documents/Publications/FTTHCouncil_AR2012_2013_Fin al.pdf [Accessed 9 April 2013].

Girres, J. F., \& Touya, G. (2010). Quality assessment of the French OpenStreetMap dataset. Transactions in GIS, 14(4), 435-459.

Given, J . (2010). Take your partners: Public private interplay in Australian and New Zealand plans for next generation broadband. Telecommunications Policy, 36(2), 96-112.

Grubesic, T. H. (2008). Spatial data constraints: Implications for measuring broadband. Telecommunications Policy, 34, 540-549.

Guenach, M., Meas, J., Timmers, M., Lamparter, O., Bischoff, J. C., \& Peeters, M. (2011). Vectoring in DSL systems: Practices and challenges. In: Proceedings of the 2011 Global Telecommunications Conference. Houston, Texas. Available at: 
http://ieeexplore.ieee.org/stamp/stamp.jsp?arnumber=06133821 [Accessed 7 April 2014].

Haklay, M. (2010). How good is volunteered geographical information? A comparative study of OpenStreetMap and ordnance survey datasets. Environment and planning. B: Planning \& Design, 37(4), 682-703.

Hoernig, S., J ay, S., Neumann, K.-H., Peitz, M., Plückebaum, T., \& Vogelsang, I. (2012). The impact of different fibre access network technologies on cost, competition and welfare. Telecommunications Policy, 36(2), 96-112.

Jay, S., Neumann, K., \& Plückebaum, T. (2014). Comparing FTTH access networks based on P2P and PMP fibre topologies. Telecommunications Policy, 38(5-6), 415-425.

Kipouridis, O., Machuca, C.M., Autenrieth, A., \&Grobe, K. (2012). Street-Aware Infrastructure Planning Tool for Next Generation Optical Access Networks. In: Proceedings of the 16th International Conference on ONDM, Colchester, pp 1-6.

Kruskal, J . B. (1956). On the shortest spanning subtree of a graph and the traveling salesman problem. In: Proceedings of the American Mathematical Society, 7(1), 48-50.

Lannoo, B., Casier, K., Van Ooteghem, J., Wouters, B., Verbrugge, S., Colle, D., Picavet, M., \& Demeester, P. (2008). Economic benefits of a community driven fiber to the home rollout. In: Proceedings of the 5th International Conference on Broadband Communications, Networks and Systems. London, England. Available at: http:/ / ieeexplore.ieee.org/ stamp/ stamp.jsp?tp=\&arnumber=4769123 [Accessed 7 April 2014].

NBNCO, nbn co limited (2015). Corporate Plan 2016, nbn - Australia's new broadband network. Available at: http:// www.nbnco.com.au/ content/ dam/ nbnco2/ documents/nbn-corporate-plan2016.pdf [Accessed 10.12.2015].

Neis, P., Zielstra, D., Zipf, A., \& Struck, A. (2010). Empirische untersuchungen zur datenqualität von OpenStreetMap - Erfahrungen aus zwei jahren betrieb mehrerer OSMonline-dienste. In: Strobl, J., Blaschke, T. \& Griesebner, G. (Eds.). Angewandte Geoinformatik 2010: Beiträge zum 22. AGIT-Symposium Salzburg. Berlin: Wichmann, 420-425.

OpenStreetMap. (2012). OpenStreetMap density of data by region. Available at: http:// www.odbl.de [Accessed 14J anuary 2013].

OpenStreetMap. (2013). OpenStreetMap. Available at: http://www.openstreetmap.org [Accessed 12 J anuary 2013].

Organisation for Economic Co-Operation and Development (OECD). (2009). Working party on communication infrastructures and services policy - Indicators of broadband coverage. Available at: http:// www.oecd.org/internet/broadband/44381795.pdf [Accessed 14 November 2013].

Pages M. \&Pe D. (2013). Will LTE kill DSL? The Delta Perspective.

Regionaldatenbank. (2013) Regionaldatenbank. Available at: https:// www.regionalstatistik.de/ genesis/ online/logon [Accessed 11 April 2013].

Robey D., Sahay S. (1996). Transforming Work Through Information Technology: A Comparative Case Study of Geographic Information Systems in County Government. Information Systems Research, 7(1), 93-110.

Rokkas, T., Katsianis, D., \&Varoutas, D. (2010). Techno-economic evaluation of FTTC/VDSL and FTTH roll-out scenarios: Discounted cash flows and real option valuation. J ournal of optical Communications and Networking, 2(9), 760-772. 
Ruhle, E. O., Brusic, I., Kittl, J., \& Ehrler, M. (2011). Next Generation Access (NGA) supply side interventions - An international comparison. Telecommunications Policy, 35(9), 794-803.

Schäfer, R. G. \& Schöbel, A. (2005). Stand der Backbone-Infrastruktur in Deutschland - Eine Markt- und Wettbewerbsanalyse. WIK Diskussionsbeiträge, Nr. 265.

Sawhney, H. (1992). Demand aggregation strategies for rural telephony. Telecommunications Policy, 16(2), 167-178.

Schneir, J. R., \& Xiong, Y. (2013). Economic implications of a co-investment scheme for FTTH/ PON architectures. Telecommunications Policy, 37(10), 849-860.

Segarra, J., Sales, V., \& Prat, J . (2012). Planning and Designing FTTH Networks: Elements, Tools and Practical Issues. In: Proceedings of the 14th ICTON, Coventry, 1-6.

Tahon, M., van Ooteghem, J ., Casier, K., Verbrugge, S., Colle, D., Pickavet, M., \& Demeester, P. (2014). Improving the FTTH business case - A joint telco-utility network rollout model. Telecommunications Policy, 38(5-6), 426- 437.

Vidmar, L., Peternel, B., Štular, M., \& Kos, A. (2010). Broadband access network investment optimization in rural areas. In: Proceedings of the 15th IEEE Mediterranean Electrotechnical Conference. Valletta, Malta. Available at: http://ieeexplore.ieee.org/stamp/stamp.jsp?tp=\&arnumber $=5476228$ [Accessed 14 September 2014].

Zielstra, D., \& Zipf, A. (2010). Quantitative studies on the data quality of OpenStreetMap in Germany. In: Proceedings of the 6th International Conference on Geographic Information Science. Zurich, Switzerland. Available at: http:// www.giscience2010.org/pdfs/paper_187.pdf [Accessed 10 February 2015].

Copyright: (C) 2016 Limbach, Kuebel \&Zarnekow. This is an open-access article distributed under the terms of the Creative Commons Attribution-NonCommercial 3.0 Australia License, which permits non-commercial use, distribution, and reproduction in any medium, provided the original author and AJ IS are credited.

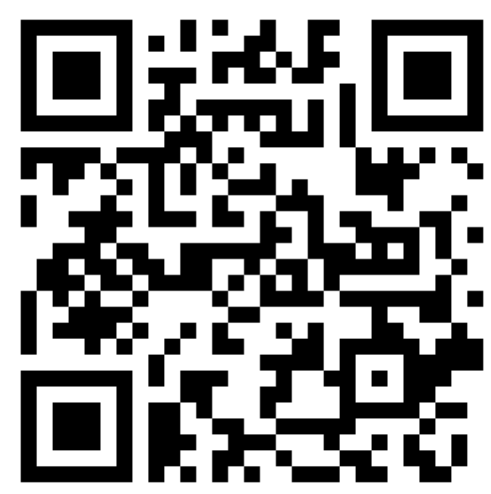

